\title{
Modeling and Experimental Validation of Carbon Dioxide Sorption on Hollow Fibers Loaded with Silica- supported Poly(ethylenimine)
}

\author{
Jayashree Kalyanaraman, Yanfang Fan, Ryan P. Lively, William J. Koros, \\ Christopher W. Jones, Matthew J. Realff, Yoshiaki Kawajiri \\ School of Chemical \& Biomolecular Engineering, Georgia Institute of Technology, 311 \\ Ferst Drive, Atlanta, GA 30332, United States
}

\begin{abstract}
A mathematical model is developed for carbon dioxide adsorption on hollow fiber post infused with physically impregnated poly(ethylenimine) silica sorbent. The model includes detailed mass transfer mechanisms and is rigorously validated under different operating conditions of flue gas flow rate, number of fibers within the module, fiber length and particle size. A fundamental model formulation for the sorbent polymer diffusivity including the temperature and the sorbent concentration dependency is proposed. The proposed model formulation is based on free volume theory model of polymer diffusion and effectively predicts the experimental observations. The model is able to predict the breakthrough curves at many different operating conditions and module designs such as conditions varied with flue gas flow rate, fiber length, fiber packing fraction and support silica particle size. The concave trend in the temperature dependency of breakthrough capacity that shows a maximum around $45^{\circ} \mathrm{C}-60^{\circ} \mathrm{C}$ is analyzed using the developed model.


Keywords: amine sorbents, mass transfer kinetic studies, poly(ethylenimine) hollow fiber, mass transfer modeling

\section{Introduction}

Carbon dioxide capture and separation from flue gas of fossil-fueled power plants is an important and an active area of research in the recent years, because of the imputed influence of greenhouse gases like $\mathrm{CO}_{2}$ on global climate change. Different categories of post combustion $\mathrm{CO}_{2}$ capture technologies including liquid amine scrubbing, absorption into ionic liquids, chemical looping combustion and adsorption on solid adsorbents, have been proposed because of its potential widespread impact on existing coal fired power plants [1]. In particular, adsorption on solid adsorbents stands out as a promising alternative due to the potential of handling higher throughput and lower energy cost for regeneration compared to the energy intensive liquid amine scrubbing technology [2].

Lively et al [3] have proposed a novel hollow fiber based sorbent system configuration that offers several advantages compared to conventional packed bed adsorption. The most notable feature of the configuration is the presence of a water impermeable lumen layer in the bore of the fiber enabling the flow of water, thereby resembling a shell and tube exchanger. By controlling the flow of water through the bore of the fiber, the adsorption heat can be potentially recovered [3]. The other significant advantage is that the fiber sorbent structure has a very low gas pressure drop compared to the packed bed flow. The organization of the sorbent into fibers reduces the tortuosity of the gas flow and the inherent frictional losses of the packed bed. A compara- 
tive study of the energy penalties among the different post combustion $\mathrm{CO}_{2}$ separation processes by Lively et al [4] showed that the zeolite MFI loaded hollow fiber adsorbents in a Rapid Thermal Swing Adsorption (RTSA) along with heat integration is very promising technology having the lowest system parasitic loads, but likely higher capital costs due to the low $\mathrm{CO}_{2}$ capacity of MFI.

While the concept of hollow fiber sorbents were proved with zeolites, supported amine sorbents were shown to be highly efficient under humid conditions [5] with a significantly higher $\mathrm{CO}_{2}$ capacity than MFI sorbents. Depending upon the mode of support for the amine sorbents on the mesoporous silica, there are two common classes of hollow fibers based amine sorbents, class1 and class2. Bollini et al and Rezeai et al [7] have studied the $\mathrm{CO}_{2}$ adsorption on hollow fiber supported amine sorbents known as class2 fibers, in which the hollow fiber is grafted with amine functionalized silica, specifically 3-aminopropyltrimethoxysilane(APS) in the reported work. The other class of supported amine sorbents, namely class1, are synthesized by physically impregnating the amine, such as poly(ethylenimine) (PEI) on to the silica support. In recent work, Fan et al [8], reported the feasibility of $\mathrm{CO}_{2}$ adsorption on hollow fibers post infused with class1 amine sorbents.

Adsorption and diffusion in amine sorbents is complex. Specifically, the $\mathrm{CO}_{2}$ breakthrough from amine sorbents can have a long tail [9]. Furthermore, the breakthrough capacity increases with an increase in temperature over a certain temperature range, and thus the breakthrough capacity has a maximum capacity at a particular temperature. In this work, we call this a concave trend of the breakthrough capacity [8]. There have been only few 
studies on modeling the $\mathrm{CO}_{2}$ breakthrough curve from supported amine sorbents and each of them uses a different approach. Supported amine sorbents with high amine loadings have been hypothesized to contain two different regions of amine sorption sites, including the ones that are easily accessible from the surface of the sorbent pores and those that are confined within the bulk of the amino polymer phase, and there have been related studies in the literature [9], [10]. Based on the characterization of PEI loaded on mesoporous silica SBA-15 materials [11], Wang et al [10] proposed that the PEI in the silica sorbents are either dispersed or confined within the mesopores. They had conducted temperature programmed desorption of $\mathrm{CO}_{2}$ over PEI impregnated mesoporous silica SBA-15 to quantify the proportion of amines in the two regions, which they named as exposed PEI layer and bulky PEI layer. Serna-Guerrero and Sayari [12] used a modified Toth adsorption isotherm as composed of two separate equilibrium terms, corresponding to physical and chemical adsorption respectively, to model the adsorption equilibrium capacity of amine functionalized silica. In addition, they used a fractional order kinetic model to describe the mass transfer kinetics of $\mathrm{CO}_{2}$ adsorption in a packed bed with amine functionalized mesoporous silica and match the $\mathrm{CO}_{2}$ breakthrough from experiments with the model. Bollini et al [9], on the other hand, proposed a similar approach to Wang et al [10], considering two different amine adsorption sites to model the $\mathrm{CO}_{2}$ breakthrough with APS functionalized silica sorbents. In recent work, Rezeai et al [13] used an empirical model for the intra-particle sorbent resistance to capture the behavior of the long tail in the $\mathrm{CO}_{2}$ breakthrough curve. While all the above works assumed the mass transfer kinetics of $\mathrm{CO}_{2}$ adsorption on amine func- 
tionalized/impregnated silica as a diffusion limited process, Ebner et al [14] assumed the chemisorption reaction rate as the rate limiting step to model the equilibrium adsorption capacity of $\mathrm{CO}_{2}$ on amine functionalized silica.

Mass transfer kinetics have been shown to have a significant impact on the adsorption capacity of $\mathrm{CO}_{2}$ on solid adsorbents[8] [9]. Without the use of a detailed mass transfer resistance model, it is difficult to quantify and understand the different components of diffusion resistances involved in a $\mathrm{CO}_{2}$ adsorption process. The model developed should be such that it predicts the experimental behavior under different operating conditions and process design parameters in order to apply it for process scalability and technology feasibility studies.

The objective of this work is development and validation of a rigorous mathematical model for $\mathrm{CO}_{2}$ adsorption on hollow fibers post infused with class1 amine sorbents, in particular PEI impregnated silica sorbents (molecular basket sorbents). The developed model is used to study and analyze the effect of mass transfer and heat transfer kinetics on $\mathrm{CO}_{2}$ adsorption performance. Factors such as the flue gas flow rate, fiber length, fiber packing fraction in a module and finally particle size of the support mesoporous silica are varied to study the mass transfer kinetics. In this paper, the developed model is rigorously validated against all the above different conditions and used further in detailed analysis of the effect of mass and heat transfer kinetics. Also, the concave trend in the temperature dependency of breakthrough capacity has been studied using the developed model. It should be noted that there has been no reported study so far on modeling the temperature dependency of breakthrough capacity for supported amine sorbents, to the 
best of our knowledge.

The organization of the rest of the paper is as follows. It starts with the mathematical modeling formulation describing the governing equations of mass, energy and momentum balance. The mass transfer resistance model with the component resistances and the amino polymer diffusion model are described in detail in the Section 3.4. The model implementation details are described in Section 4. The subsequent section, Section 5.1 deals with the estimation of adsorption isotherm parameters from the thermogravimetric analysis (TGA) experiments and polymer diffusion and heat loss parameters from the $\mathrm{CO}_{2}$ adsorption breakthrough experiments, respectively. The component mass transfer resistances are analyzed and investigated in detail in the Section 5.2. Section 5.3 presents the different validation cases against the different factors that are used to study the mass transfer kinetics. Finally, the validated model is used to understand the concave trend in the temperature dependency of breakthrough capacity.

\section{Experimental setup}

The details of hollow fiber sorbents spinning and amine functionalization method can be found in previous work [15]. The fiber sorbent is a hybrid matrix composed of cellulose acetate (CA) (Sigma-Aldrich) and commercial silica particles (C803, W.R.Grace or ES757, PQ corporation) with silica loading of $57 \mathrm{wt} \%$. The experimental setup of the RTSA test station is shown in Fig.1. Unless otherwise mentioned, the ambient temperature of the test setup is maintained at $35^{\circ} \mathrm{C}$ and $1 \mathrm{~atm}$. Inlet flue gas entering the setup is of

dry gas composition containing $14 \% \mathrm{He}, 14 \% \mathrm{CO}_{2}$ and the rest $\mathrm{N}_{2}$. All the 
$\mathrm{CO}_{2}$ experiments mentioned in this paper are conducted with a hollow fiber membrane module made of copper $\left(d_{\text {imod }}=0.152 \mathrm{in}\right)$ with no flow of cooling water through bore of the fiber. The hollow fiber radial dimensions for all the experimental runs are kept fixed at $d_{I D}=550 \mu \mathrm{m}$ and $d_{o D}=1305 \mu \mathrm{m}$. Except for the experiment for varying the silica particle size, all other experiments were conducted with hollow fiber post-infused with PEI impregnated C803 silica. To investigate the effect of the particle size, $\mathrm{CO}_{2}$ breakthrough experiments using the hollow fiber membrane module loaded with PEI impregnated ES757 silica were also performed as discussed in detail in Section 5.3.4.

Prior to the start of each $\mathrm{CO}_{2}$ breakthrough experiment, the module is completely purged with $\mathrm{N}_{2}$ flow at $80 \mathrm{~mL} / \mathrm{min}$ for 30 minutes at $90^{\circ} \mathrm{C}$ to ensure removal of remnant $\mathrm{CO}_{2}$ or $\mathrm{H}_{2} \mathrm{O}$ in the system. As mentioned earlier, 
different $\mathrm{CO}_{2}$ breakthrough experiments were performed varying the flue gas flow rate $Q_{\text {fluegas }}$, length of the fiber module $L$, number of fibers packed in the module and the support sorbent particle size $d_{s}$. Measurements of $\mathrm{CO}_{2}$ concentration at the exit of the system and the fiber temperature at the middle of the module are recorded for all the experiments and used in the model validation. The dead volume time in the $\mathrm{CO}_{2}$ breakthrough curve are accounted for by subtracting the breakthrough profile of He. The breakthrough capacity of $\mathrm{CO}_{2}$ is calculated as the area between the He and $\mathrm{CO}_{2}$ curve till breakthrough time $t_{b}$. Here breakthrough time $t_{b}$ is defined as the time instant at which $\left.C_{g, c o_{2}}\right|_{z=L}=0.05 C_{0}$ is satisfied.

\section{Mathematical modeling formulation}

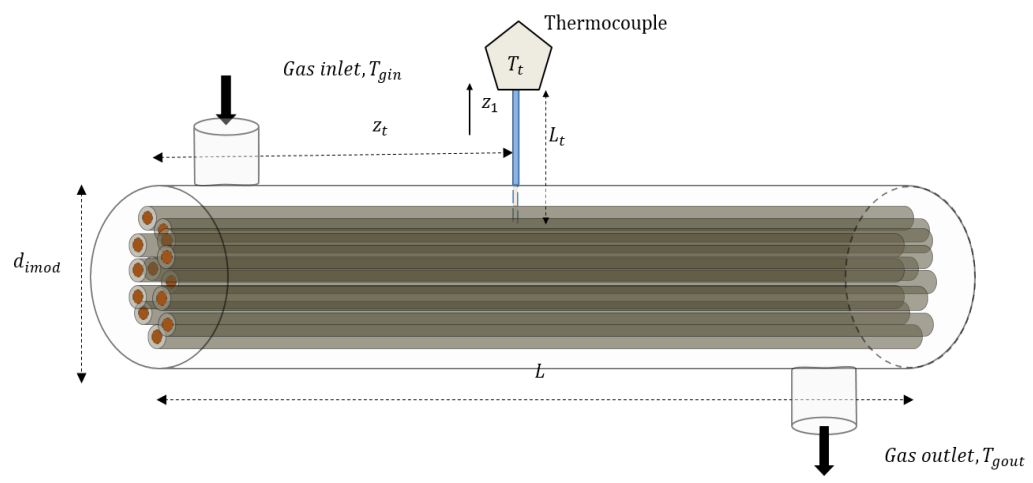

Figure 2: Schematic of the hollow fiber membrane module with thermocouple

As shown in Fig.2, a hollow fiber sorbent module is comprised of a number of identical fibers housed within the module resembling a shell and tube heat exchanger. Adopting the approach of Happel [16] in his treatment of flow parallel to an array of cylinders, the hollow fiber sorbent module is modeled 


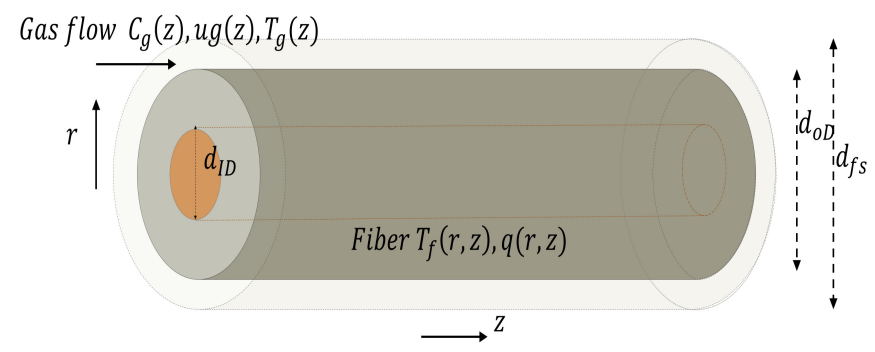

Figure 3: Schematic of a single hollow fiber

by assuming that each fiber is surrounded by a gas shell with the hypothetical boundary defined as Happel's free surface diameter, $d_{f s}$ as shown in Fig.3. Accordingly, the heat transfer to the fibers across the module wall is assumed to be across the hypothetical boundary for each fiber. Thus, modeling a single fiber can be used to understand the module behavior with the underlying assumption that the fibers are identically aligned against one another as rigid cylinders in a module [13]. The other basic assumptions underlying the model formulation are listed as follows.

- Ideal gas law is assumed for the gas phase.

- Radial gradients for the bulk gas phase concentration, velocity and temperature are neglected.

- $\mathrm{N}_{2}$ and $\mathrm{He}$ are the non adsorbing components in the gas.

\subsection{Mass balance equations}

Mass balance equations for each of the components, viz. $\mathrm{CO}_{2}, \mathrm{He}$ and $\mathrm{N}_{2}$ flowing in the shell side of the fiber defined by the boundary $r \epsilon\left(r_{o D}, r_{f s}\right)$ is 
given by:

$$
\frac{\partial C_{g, i}}{\partial t}+\frac{\partial\left(u_{g} C_{g, i}\right)}{\partial z}-D_{a x} \frac{\partial^{2} C_{g, i}}{\partial z^{2}}+S_{i}=0
$$

in which the indices $i$ refer to the components $\mathrm{CO}_{2}, \mathrm{He}$, and $\mathrm{N}_{2}$ respectively. In the above equation, $D_{a x}$ is the axial dispersion coefficient which is included to account for the effect of shear flow dynamics on concentration diffusion along the axial direction and $S_{i}$ is the source term denoting the rate of addition or removal of $i^{\text {th }}$ component from the bulk gas phase. The boundary conditions of component concentrations $C_{g, i}$ are $C_{g, i_{z=0}}=y_{g, i} P /\left.R T_{g}\right|_{z=0}$ and $\partial C_{g, i} /\left.\partial z\right|_{z=L}=0$, where $y_{g, i}$ is the $i^{t h}$ component mole fraction of the inlet flue gas, $P$ is the pressure and $T_{g}$ is the temperature of the bulk gas phase. The source terms for each of the components are modeled as follows.

$$
\begin{aligned}
S_{C O_{2}} & =\frac{\partial q}{\partial t} \rho_{f}\left(1-\epsilon_{f}\right) \frac{r_{o D}^{2}-r_{I D}^{2}}{r_{f s}^{2}-r_{o D}^{2}} \\
S_{N_{2}} & =0 \\
S_{H e} & =0
\end{aligned}
$$

The mass balance of the hollow fiber sorbent phase and the mass transfer resistance model are described in detail in the Section 3.4.

\subsection{Energy balance equations}

\subsubsection{Adsorption heat loss}

The total heat of adsorption involved, even on complete sorbent saturation, is relatively small in the labscale module with few number of fibers (approximately $65 \mathrm{~J}$ ). In effect, the adsorption heat gets rapidly lost to the 
module heat capacity and possibly to the thermocouple heat capacity, which are assumed to the major heat sinks in the system. The mode of heat loss to the module is via convection from the fiber to gas and then from gas to the module. The other heat loss component which is from fiber to thermocouple is via conduction between the module and the thermocouple, shown in Fig.2. This heat loss source is modeled by using an overall heat transfer coefficient for the interface between thermocouple and module, $h_{t}$. There could be perhaps, some other modes of heat loss such as direct conduction between the fibers wherever they are in contact with one another or by conduction to the ends of the module. These, however, are not included in the heat transfer model, to avoid unnecessary complexity in the model and due to the fact that the current formulation adequately describes the experimental observations.

\subsubsection{Components of system energy balance}

Energy balance of the fiber is given in Eqn.(7),

$$
\begin{array}{r}
\rho_{f} C_{p, f}\left(1-\epsilon_{f}\right) \frac{\partial T_{f}}{\partial t}-\lambda_{f} \frac{1}{r} \frac{\partial}{\partial r}\left(r \frac{\partial T_{f}}{\partial r}\right)-\lambda_{f} \frac{\partial^{2} T_{f}}{\partial z^{2}}-\frac{\partial q}{\partial t}\left(-\Delta H_{a d s}\right)\left(1-\epsilon_{f}\right) \rho_{f} \\
+h_{t}\left(\left.T_{f}\right|_{r=r_{o D}, z=z_{t}}-\left.T_{t}\right|_{z_{1}=0}\right) \frac{A_{t}}{\left(r_{o D}^{2}-r_{I D}^{2}\right) L}=(70)
\end{array}
$$

where $\Delta H_{a d s}$ is the average isosteric heat of adsorption. The axial boundary conditions of the fiber temperature, $T_{f}$ are given by $\partial T_{f} /\left.\partial z\right|_{z=0}=\partial T_{f} /\left.\partial z\right|_{z=L}=$ 0 . The boundary conditions in the radial domain are given by $\partial T_{f} /\left.\partial r\right|_{r=r_{I D}}=$ 0 and $-\lambda_{f} \partial T_{f} /\left.\partial r\right|_{r=r_{o D}}=h_{g}\left(\left.T_{f}\right|_{r=r_{o D}}-T_{g}\right)$.

Heat transfer within the thermocouple needle is modeled using a one dimensional heat diffusion equation along the dimension $z_{1}$ as given by the 
following equation:

$$
\rho_{t} C_{p, t} \frac{\partial T_{t}}{\partial t}-\lambda_{t} \frac{\partial^{2} T_{t}}{\partial z_{1}^{2}}=0
$$

In this model, the heat from the fiber is conducted via the tip of the thermocouple needle where it touches the fiber. Fig.2 shows a schematic of the representation of the thermocouple along with the other relevant thermocouple parameters. The boundary conditions of the thermocouple temperature are as follows.

$$
\begin{array}{r}
-\lambda_{t} \frac{\partial T_{t}}{\partial z_{1}}=h_{t}\left(\left.T_{f}\right|_{r=r_{o D}, z=z_{t}}-\left.T_{t}\right|_{z_{1}=0}\right) \\
\left.T_{t}\right|_{z_{1}=L_{t}}=T_{a m b}
\end{array}
$$

Here, $h_{t}$ is the overall heat transfer coefficient of the thermocouple and the module and $A_{t}$ is the cross section area of the thermocouple tip (Fig.2). The end of the thermocouple is exposed to the ambient conditions of the experimental test station which is referred to as $T_{a m b}$.

The energy balance of the gas phase is given as follows.

$$
\begin{aligned}
\rho_{g} C_{p, g} \frac{\partial T_{g}}{\partial t}+\frac{\partial\left(T_{g} u_{g}\right)}{\partial z}-\lambda_{g} \frac{\partial^{2} T_{g}}{\partial z^{2}}+ & h_{g} \frac{2 r_{o D}}{r_{f s}^{2}-r_{o D}^{2}}\left(T_{g}-\left.T_{f}\right|_{r_{o D}}\right) \\
& +U \frac{2 r_{f s}}{r_{f s}^{2}-r_{o D}^{2}}\left(T_{g}-T_{a m b}\right)=0
\end{aligned}
$$

where $h_{g}$ is the gas convective heat transfer coefficient calculated using the Chilton Colburn analogy [18]. The boundary conditions for the gas temperature, $T_{g}$ are $\left.T_{g}\right|_{z=0}=T_{g i n}$ and $\left.T_{g}\right|_{z=L}=T_{a m b}$.

\subsection{Momentum balance equations}

The momentum balance of the bulk gas phase is modeled assuming that the momentum of the gas adsorbed is lost along with loss of its mass from 
the bulk phase. The gas phase momentum balance as given below, is same as Happel's model [16] which considers an incompressible flow through the shell side of a set of cylinders.

$$
u_{g}(z)=-\frac{d P}{d z} \frac{1}{\mu_{g}}\left(\frac{\left(r_{o D}^{2}-3 r_{f s}^{2}\right)}{8}+\frac{r_{f s}^{4}}{2\left(r_{f s}^{2}-r_{o D}^{2}\right)} \ln \left(\frac{r_{f s}}{r_{o D}}\right)\right)
$$

In this study, however, the velocity is not constant along the axial dimension, as the pressure drop varies with time during the time frame of adsorption. The pressure gradient is calculated using ideal gas law as follows.

$$
\frac{d P}{d z}=R_{g} \sum_{i=C O_{2}, H e, N_{2}}\left(T_{g} \frac{\partial C_{g, i}}{\partial z}+C_{g, i} \frac{\partial T_{g}}{\partial z}\right)
$$

The boundary conditions for pressure and velocity are given as follows: $\partial P /\left.\partial z\right|_{z=0}=0, P_{z=L}=P_{a t m}, u_{g}=u_{\text {gin }}$ and $\partial u_{g} /\left.\partial z\right|_{z=L}=0$.

\subsection{Mass transfer resistance model}
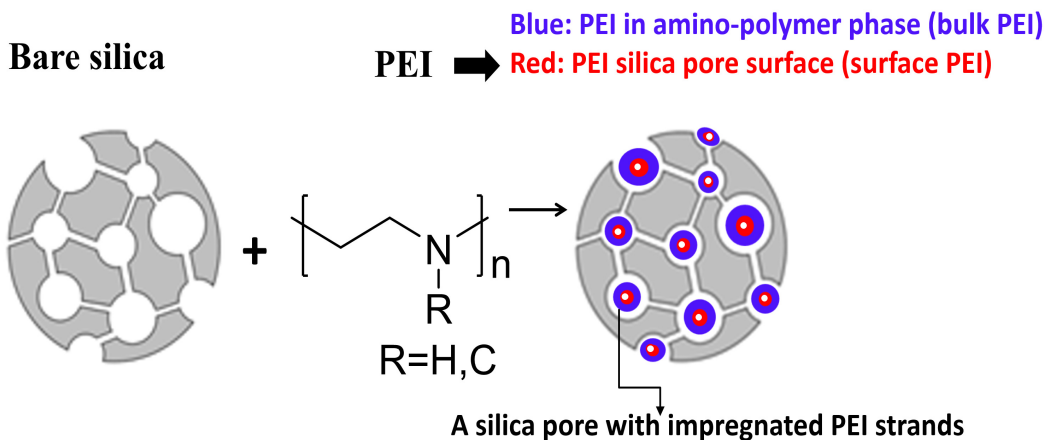

Figure 4: Schematic of the two regions of amine adsorption sites 
In this work, $\mathrm{CO}_{2}$ diffusion rather than reaction is assumed as the rate limiting step in the chemisorption of $\mathrm{CO}_{2}$ on poly(ethylenimine) sorbent. Conventional mass transfer resistance models used for packed beds have been unable to describe the $\mathrm{CO}_{2}$ breakthrough from amine sorbents, which has an asymmetric shape with a sharp breakthrough and a long tail [9], [12], [13]. A modification to the conventional mass transfer resistance model is thus required. Here, it is assumed that the adsorption sites are available in two regions within the sorbent, including the ones which are easily accessible being on the surface of the sorbent pores (surface PEI) and the other which are more confined within the amino polymer phase in the silica particle (bulk PEI). This assumption is similar to the hypothesis in Wang et al[10] and Bollini et al [9]. Accordingly, the mode of diffusion is assumed to be Knudsen diffusion (as mean free path, $\lambda$ of $\mathrm{CO}_{2}=100 \mathrm{~nm}>d_{s, \text { pore }}=20 \mathrm{~nm}$ ) to the surface amine sites and hindered polymer diffusion to the sites in aminopolymer phase. Fig.4 schematically depicts the two different amine sites, as described which could be occurring in the PEI impregnated mesoporous silica.

The mass balance of the sorbent phase is modeled using Linear Driving Force model (LDF) as shown in the following equations,

$$
\begin{aligned}
\frac{\partial q_{1}}{\partial t} & =K_{o v, k}\left(q_{e q} \psi-q_{1}\right) \\
\frac{\partial q_{2}}{\partial t} & =K_{o v, p}\left(q_{e q}(1-\psi)-q_{2}\right) \\
q & =q_{1}+q_{2}
\end{aligned}
$$

where $q_{1}$ and $q_{2}$ refer to the $\mathrm{CO}_{2}$ concentration in the surface sites and in the amino-polymer sites respectively. Here, $\psi$ is the ratio of the adsorption sites 
available on the surface PEI to the total PEI and is defined as follows.

$$
\psi=\frac{N_{s}}{N_{t}}
$$

where $N_{s}$ is the number of amine sites available on the surface of the sorbent pores per unit weight of sorbent and $N_{t}$ refers to the total number of amine sites available per unit weight of sorbent.

Since adsorption is assumed to occur in two different sites each with different modes of diffusion, separate mass balance equations are written for each of the sites with the respective overall mass transfer coefficient and the corresponding driving force Eq.15 and Eq.16. Out of the total maximum adsorption capacity $q_{e q}$ of the sorbent, only $\psi q_{e q}$ is available on the surface of the sorbent particle. Accordingly, the driving force is modified as $\psi q_{e q}-q_{1}$. Similarly, the driving force for the amino-polymer sites is modified considering the remaining equilibrium adsorption capacity.

It is to be noted that the formulation of LDF model for the two adsorption sites as in Eq.15-Eq.16 is similar to the one reported in Bollini et al [9]. The difference is that, while Bollini et al [9] had used a lumped mass transfer coefficient parameter to describe the diffusion resistance, we have developed a more detailed mass transfer resistance model for each of the phase components and is described in the following section.

\subsubsection{Overall mass transfer resistance}

Under the assumption that the accumulation of $\mathrm{CO}_{2}$ within the macropores of the fiber is significantly smaller than the amount adsorbed in the sorbent, an overall mass transfer coefficient corresponding to the overall concentration driving force between the gas phase $C_{g, c_{2}}$ and the sorbent phase 


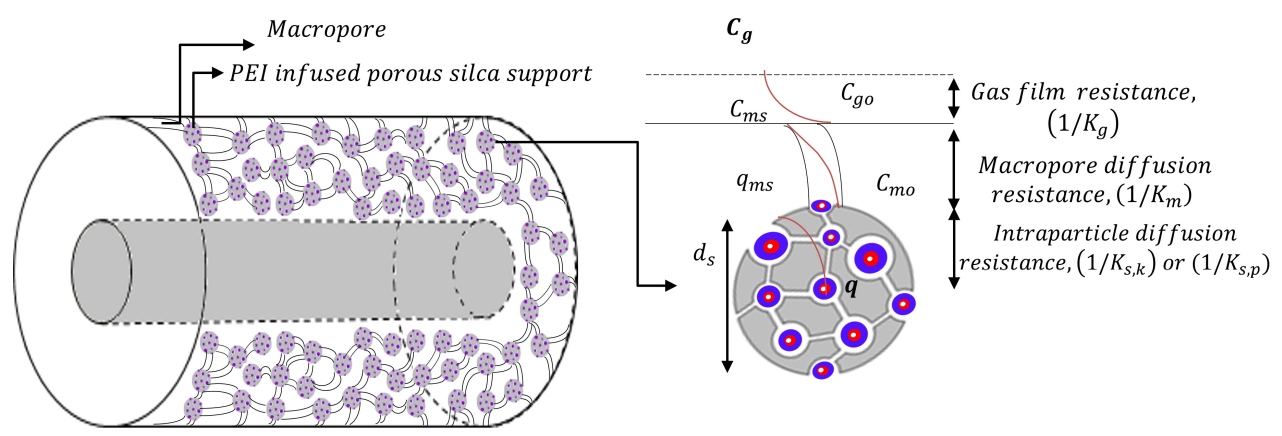

Figure 5: Schematic of the component mass transfer resistances, $C_{g o}, C_{m o}, C_{m s}$ and $q_{m s}$ are the interface resistances of gas, gas-macropore, macropore, macropore-micropore and sorbent surface respectively (see supplementary material for more details).

$q$, is used in the present work. This, in effect, eliminates a partial differential equation that needs to be solved for the mass balance of the $\mathrm{CO}_{2}$ concentration in the fiber macropores. Fig.5 schematically describes the individual phase resistances and the respective concentration gradients in each phase of the hollow fiber membrane. Despite of the simplification discussed above, the resistance offered by the fiber macropores, gas phase and the sorbent phase are rigorously accounted and the the overall mass transfer coefficient is obtained as sum of the individual resistances (as the resistances are in series) for both the adsorption sites and are as follows.

$$
\begin{aligned}
& \frac{1}{K_{o v, k}}=\frac{1}{K_{g}}+\frac{1}{K_{m}}+\frac{1}{K_{s, k}} \\
& \frac{1}{K_{o v, p}}=\frac{1}{K_{g}}+\frac{1}{K_{m}}+\frac{1}{K_{s, k}}+\frac{1}{K_{s, p}}
\end{aligned}
$$

where $1 / K_{g}$ and $1 / K_{m}$ refer to the diffusion mass transfer resistances in the gas phase and the fiber macropore phase respectively. In addition, $1 / K_{s, k}$ and $1 / K_{s, p}$ refer to the diffusion mass transfer resistances to the surface PEI 
layer and bulk PEI layer respectively. Fiber macropore resistance $1 / K_{m}$ is henceforth referred to as inter-particle resistance, and the sorbent phase resistance is referred to as intra-particle resistances which are intraparticle surface diffusion resistance $1 / K_{s, k}$ and intra-particle polymer diffusion resistance $1 / K_{s, p}$. The model for each of the component resistances is derived from the first principles and shown in Eq.(21-24) (see Section.1 in the supplementary material for derivation).

$$
\begin{aligned}
K_{g} & =\frac{2 k_{g} \epsilon_{f} r_{o D}}{\left(r_{o D}^{2}-r_{I D}^{2}\right) \frac{\partial q_{e q}}{\partial C_{g, c o_{2}}} \rho_{f}\left(1-\epsilon_{f}\right)} \\
K_{m} & =\frac{8 r_{o D}^{2} D_{f p} \epsilon_{f}}{\left(r_{o D}^{2}-r_{I D}^{2}\right)^{2} \frac{\partial q_{e q}}{\partial C_{g, c_{2}}}\left(1-\epsilon_{s}\right) \rho_{f}\left(1-\epsilon_{f}\right)} \\
K_{s, k} & =\frac{15 D_{p, k} \epsilon_{s}}{r_{s}^{2} \frac{\partial q_{e q}}{\partial C_{g, c_{2}}} \psi\left(1-\epsilon_{s}\right) \rho_{s}} \\
K_{s, p} & =\frac{15 D_{p} \epsilon_{s}}{r_{s}^{2} \frac{\partial q_{e q}}{\partial C_{g, c_{2}}}(1-\psi) \rho_{s}}
\end{aligned}
$$

wherein $k_{g}$ is the gas convective mass transfer coefficient, $D_{f p}$ is the macropore gas diffusivity, $D_{p, k}$ is the Knudsen diffusion in the sorbent micropore and $D_{p}$ is the sorbent polymer diffusivity. Knudsen diffusivity within the sorbent micropore is calculated as follows.

$$
D_{p, k}=\frac{d_{s, p o r e}}{3} \sqrt{\frac{8 R_{g} T_{g}}{\pi M_{c o_{2}}}}
$$

where $d_{s, p o r e}$ is the sorbent pore diameter and $M_{\mathrm{co}_{2}}$ is the molecular weight of $\mathrm{CO}_{2}$. The gas convective mass transfer coefficient $k_{g}$ is estimated within the model using the correlation relating Sherwood number $S h=k_{g} r_{h} / D_{g}$ to Reynolds $R e=2 \rho_{g} u_{g} r_{f s} / \mu_{g}$ and Schmidt number $S c=\mu_{g} / \rho_{g} D_{g}$ from 
Asimakopoulou et al[17] as follows.

$$
S h=1.45\left(\operatorname{Re} S c \frac{d_{o}}{L}\right)^{0.33}
$$

In the Sherwood number $S h, D_{g}$ refers to the molecular diffusivity of $\mathrm{CO}_{2}$ in $N_{2}$ and calculated using the Chapman and Enskog equation [18]. Effective hindered molecular diffusivity in fiber macropore, $D_{f p}$ is calculated using using the following equation.

$$
D_{f p}=D_{g} \frac{\epsilon_{f}}{\tau_{f}}
$$

\subsubsection{Model for amino-polymer diffusion coefficient}

Diffusion in the bulk PEI is considered slow, which causes a long tail in the $\mathrm{CO}_{2}$ adsorption breakthrough curve. Unless the diffusion is modeled carefully, the model would not be able to predict the breakthrough curves. In this study, we apply a diffusion model to diffusivity in the amino-polymer phase of PEI, which is a long chain of amines.

Diffusivity in polymers have been most commonly estimated using free volume theory which considers the diffusivity to be proportional to the free volume available within the polymer as follows [19].

$$
D_{\text {polymer }} \propto e^{-B / v_{f}}
$$

where $v_{f}$ is the free volume within the polymer molecule and the $B$ is the volume of the penetrant molecule. Since poly(ethylenimine) is a polymer that consists of a repeating unit of amine group and two aliphatic groups, we use an analogous formulation to model the sorbent polymer diffusivity as follows.

$$
D_{p}=D_{p 0}^{\prime} e^{-\alpha q_{2}}
$$


In the above equation, $\mathrm{CO}_{2}$ concentration in the bulk PEI $q_{2}$ can be understood as inversely proportional to free volume within the bulk PEI. Also, $\alpha$ can be understood as a parameter describing the rate at which sorbent $\mathrm{CO}_{2}$ concentration reduces the free volume in the amino-polymer within the sorbent and thus effectively decreasing the polymer diffusivity with the progress of adsorption. Additionally, temperature has a significant influence on the diffusion coefficients $D_{p 0}^{\prime}$ in polymer and hence the temperature dependency is also included according to Arrhenius relation as follows.

$$
D_{p 0}^{\prime}=D_{p 0} e^{-E / R T_{g}}
$$

where $E$ is the activation energy for diffusion and $\mathrm{R}$ is the gas constant. Combining the above two equations, the sorbent polymer diffusivity $D_{p}$ can be written as follows.

$$
D_{p}=D_{p 0} e^{-E / R T_{g}} e^{-\alpha q_{2}}
$$

Rezeai et al [13] have reported a similar formulation for the sorbent mass transfer resistance in which the exponential dependency was defined with respect to the coverage $q / q_{e q}$. The current formulation, on the other hand, is based on the free volume theory of polymer diffusion in addition to the inclusion of temperature dependency.

\section{5. $\mathrm{CO}_{2}$ adsorption isotherm}

Equilibrium adsorption capacity of $\mathrm{CO}_{2}$ in the sorbent phase, $q_{e q}$ is determined using the Toth adsorption isotherm as follows.

$$
\frac{q_{e q}}{q_{m}}=\frac{b C_{g, \mathrm{co}_{2}}}{\left(1+\left(b C_{g, \mathrm{co}_{2}}\right)^{n}\right)^{1 / n}}
$$


The temperature dependency of the affinity constant $b$, maximum sorption capacity $q_{m}$ and heterogeneity constant $n$ are modeled in the following equations,

$$
\begin{aligned}
b & =b_{0} e^{\left.-\frac{\Delta H_{0}}{R_{g} T_{0}} \frac{T_{0}}{T}-1\right)} \\
q_{m} & =q_{m_{0}} e^{\left(\eta\left(1-\frac{T}{T_{0}}\right)\right)} \\
n & =A+B\left(1-\frac{T_{0}}{T}\right)
\end{aligned}
$$

where $b_{0}$ is the affinity constant at reference temperature $T_{0}, \Delta H_{0}$ is the isosteric heat of adsorption at zero loading, $\eta$ is the parameter defining the temperature dependency of maximum saturation capacity $q_{m}$, and $q_{m 0}$ is the maximum saturation capacity at $T_{0}$. Finally, $A$ and $B$ are the parameters defining the temperature dependency of the heterogeneity constant $n$.

\section{Model implementation}

The simulations and the parameter estimation are performed using gPROMS which is a commercial dynamic process modeling and optimization software. In gPROMS, the governing equations are solved using method of lines with a finite difference based discretization for the spatial derivatives. For all the simulations reported in this work, Backward Finite Difference (BFD) was used to discretize axial derivatives in all the equations except momentum balance and the Central Finite Difference (CFD) was used for the radial derivatives. The momentum balance equation is discretized using Central Finite Difference (CFD). The parameter estimation in gPROMS is formulated as maximum likelihood estimation problem [21]. The values of the process parameters are given in Table.1. 
Table 1: Values of physical properties and process parameters

\begin{tabular}{|c|c|c|}
\hline Physical Properties and parameters & Symbol & Values \\
\hline Fiber heat capacity $[\mathrm{J} / \mathrm{kgK}]$ & $C_{p f}$ & 1200 \\
\hline Flue gas heat capacity $[\mathrm{J} / \mathrm{KgK}]$ & $C_{p g}$ & 1094 \\
\hline Flue gas viscosity $[\mathrm{kg} / \mathrm{ms}]$ & $\mu_{g}$ & $1.98 \times 10^{-5}$ \\
\hline Fiber bulk density with $\mathrm{C} 803\left[\mathrm{~kg} / \mathrm{m}^{3}\right]$ & $\rho_{f}$ & 960 \\
\hline Fiber bulk density with ES757 $\left[\mathrm{kg} / \mathrm{m}^{3}\right]$ & $\rho_{f}$ & 700 \\
\hline Fiber conductivity $[\mathrm{W} / \mathrm{mK}]$ & $k$ & 0.05 \\
\hline Fiber tortuosity & $\tau_{f}$ & 2.5 \\
\hline Fiber porosity & $\epsilon_{f}$ & 0.48 \\
\hline Sorbent porosity (C803) & $\epsilon_{s}$ & 0.3 \\
\hline Sorbent density (C803) & $\rho_{s}$ & 800 \\
\hline Sorbent porosity (ES757) & $\epsilon_{s}$ & 0.08 \\
\hline Sorbent density (ES757) & $\rho_{s}$ & 200 \\
\hline Sorbent pore diameter $[\mathrm{nm}]$ & $d_{s, p o r e}$ & 20 \\
\hline Sorbent particle diameter $(\mathrm{C} 803)[\mu \mathrm{m}]$ & $d_{s}$ & 4 \\
\hline Sorbent particle diameter(ES757) $[\mu \mathrm{m}]$ & $d_{s}$ & 25 \\
\hline Volume loading $(\mathrm{C} 803)\left(\operatorname{vol}_{\text {sorbent }} / \operatorname{vol}_{\text {fiber solids }}\right)$ & $v_{s}$ & 0.684 \\
\hline Volume loading $(\mathrm{ES} 757)\left(\mathrm{vol}_{\text {sorbent }} / \mathrm{vol}_{\text {fiber solids }}\right)$ & $v_{s}$ & 2.2 \\
\hline Gas constant $[\mathrm{J} / \mathrm{mol} \mathrm{K}]$ & $R_{g}$ & 8.314 \\
\hline Thermocouple heat capacity $[\mathrm{J} / \mathrm{kg} \mathrm{K}]$ & $C_{p t}$ & 500 \\
\hline Thermocouple tip diameter $[\mathrm{m}]$ & $d_{t}$ & $0.9 \times 10^{-3}$ \\
\hline Thermocouple needle length $[\mathrm{m}]$ & $L_{t}$ & 0.05 \\
\hline Thermocouple conductivity $[\mathrm{W} / \mathrm{mK}]$ & $k_{t}$ & 16 \\
\hline Average heat of adsorption $[\mathrm{J} / \mathrm{mol}]$ & $\Delta H_{a d s}$ & $-59.0 \times 10^{3}$ \\
\hline
\end{tabular}


Table 2: Estimated adsorption isotherm parameters

\begin{tabular}{ll}
\hline Parameters & Values \\
\hline$q_{m 0}$ & $1.33 \mathrm{mmol} / \mathrm{g}$-fiber \\
$\eta$ & 1.93 \\
$A$ & 0.506 \\
$B$ & 3.403 \\
$b_{0}$ & $1.109 \times 10^{3} \mathrm{bar}^{-1}$ \\
$\Delta H_{0}$ & $-65.6 \mathrm{~kJ} / \mathrm{mol}$ \\
\hline
\end{tabular}

\section{Results and discussion}

\subsection{Parameter estimation}

\subsubsection{Estimation of isotherm parameters}

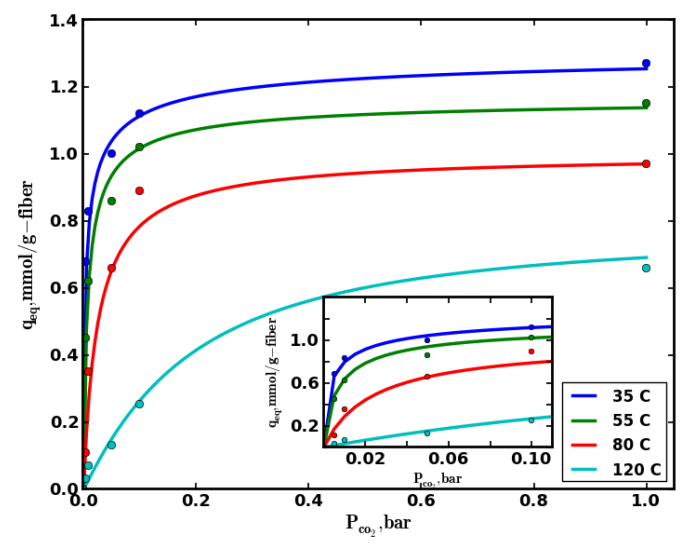

Figure 6: Model prediction of $\mathrm{CO}_{2}$ equilibrium concentration, dotted points are data from TGA experiments

Toth isotherm parameters are obtained by multivariate linear regression of the isotherm model (Eqn.32-35) with the data obtained from TGA experiments [7]. Sorption capacity at different temperatures were used to estimate 
the constants defining the temperature dependent parameters. Fig.6 shows the match obtained between the Toth adsorption isotherm model and the experimental data. The estimated adsorption isotherm parameters are shown in Table.2.

\subsubsection{Estimation of $\psi$, fraction of surface amine sites}

Strong correlation between $\psi$ and $D_{p 0}$ makes it difficult to obtain unique values of the parameters via estimation using breakthrough experimental data. Therefore, existing experimental data of Wang et al[10] on PEI impregnated in a different silica, SBA-15 is used to estimate the value of $\psi$. As SBA-15 has a different surface area than C803 used in this work, the surface area that is covered by poly(ethylenimine) is estimated using the data from Wang et al [11]. The amine loading values and the surface area measurement of C803 that are used in the calculation are obtained from Labreche et al [15]. Based on the available measurements, value of $\psi$ is calculated to be 0.17 , i.e $17 \%$ of the total amine (PEI) sites are available on the surface of the C803 silica pores. The details of the calculation can be found in the Appendix A.

\subsubsection{Estimation of sorbent-polymer diffusivity and heat loss parameters}

The sorbent polymer diffusion parameters $D_{p 0}, E$ and $\alpha$ along with the heat loss parameters $h_{t}, U$ and axial dispersion coefficient $D_{a x}$ are estimated by matching the $\mathrm{CO}_{2}$ breakthrough and temperature profile measurements with model prediction. The breakthrough data for parameter estimation are obtained using hollow fiber module containing six fibers of length $L=$ $10.25 \mathrm{in}$. Data collected at a flue gas flow rate of $Q_{\text {fluegas }}=120 \mathrm{~mL} / \mathrm{min}$ and different temperatures viz. $35^{\circ} \mathrm{C}, 45^{\circ} \mathrm{C}, 55^{\circ} \mathrm{C}$ and $65^{\circ} \mathrm{C}$ are used. 
The involved parameters are estimated sequentially. In the first step, some parameters are estimated only from the breakthrough data at $35^{\circ} \mathrm{C}$. In this step, the values of the mass transfer parameters $\alpha, D_{a x}, D_{p 0}^{\prime}$ and heat loss parameters $U$ and $h_{t}$ are obtained by matching the model with the $\mathrm{CO}_{2}$ breakthrough and temperature experimental profile at $35^{\circ} \mathrm{C}$. Fig.7 shows the match obtained between the model the experimental data while estimating the above mentioned parameters at $35{ }^{\circ} \mathrm{C}$. In this figure, the temperature values are plotted as difference in fiber temperature with the initial fiber temperature, $\Delta T_{t}(t)=T_{t}(t)-\left.T_{t}\right|_{t=0}$. In the subsequent step, the rest of the parameters are estimated using the breakthrough data at all temperatures. In this step, the parameters $\alpha, D_{a x}, U$ and $h_{t}$ are then fixed at the estimated values and value of sorbent polymer diffusivity $D_{p 0}^{\prime}$ at different temperatures such as $45^{\circ} \mathrm{C}, 55^{\circ} \mathrm{C}$ and $65^{\circ} \mathrm{C}$ are estimated by matching the model with respective experimental profile of $\mathrm{CO}_{2}$ breakthrough curve and fiber temperature. The match obtained between the experiments and the model for each of the different temperatures are shown in the Section 2 of the supplementary material. The parameters, $D_{p 0}$ and $E$ defining temperature dependency (Eq.30) of the sorbent polymer diffusion coefficient are then determined by performing a linear regression of $\log \left(D_{p 0}^{\prime}\right)$ against $1 / T$. Fig.8 shows the model prediction of the sorbent polymer diffusivity $D_{p 0}^{\prime}$ for different temperatures against the individually estimated values for the discrete temperatures. Table.3 summarizes the values of all the estimated mass and heat transfer parameters. 


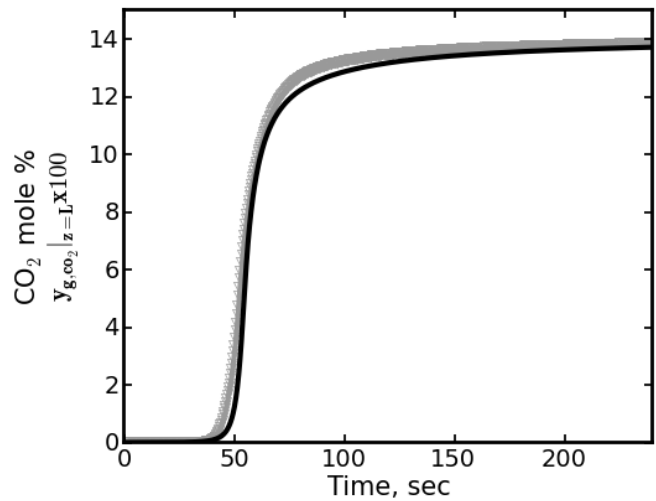

(a) $\mathrm{CO}_{2}$ breakthrough profile

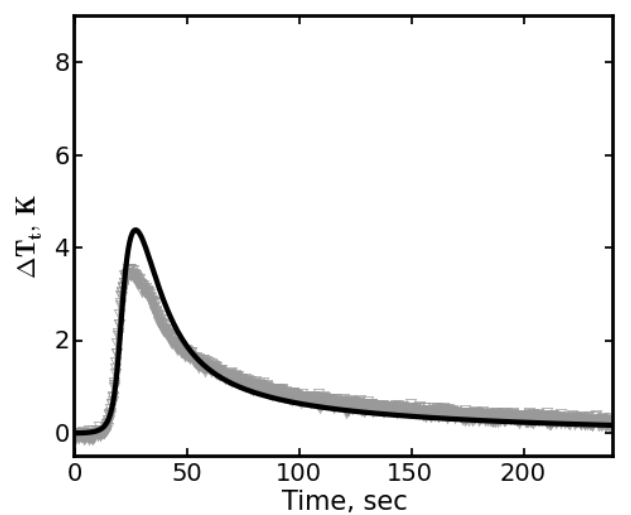

(b) Fiber temperature rise $\left.\Delta T_{t}\right|_{z=z_{t}}$ at $\mathrm{z}=4.5$ in

Figure 7: Model fitting of $\mathrm{CO}_{2}$ and temperature profile with estimated parameters at $Q_{\text {fluegas }}=120 \mathrm{~mL} / \mathrm{min}$ and $35^{\circ} \mathrm{C}$

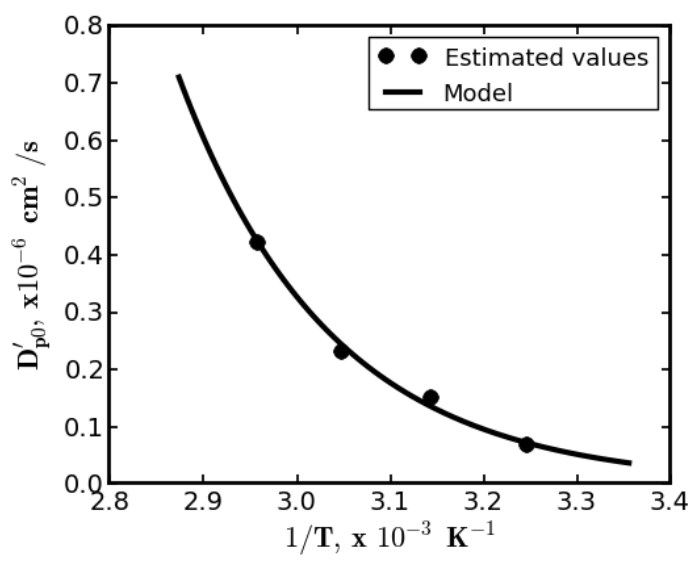

Figure 8: Temperature dependency of polymer diffusivity $D_{p 0}^{\prime}$ 


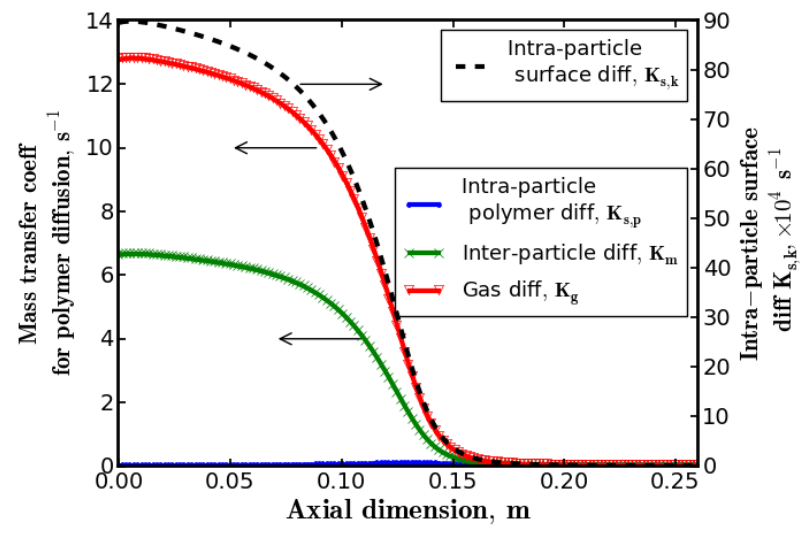

(a) Component mass transfer coefficients

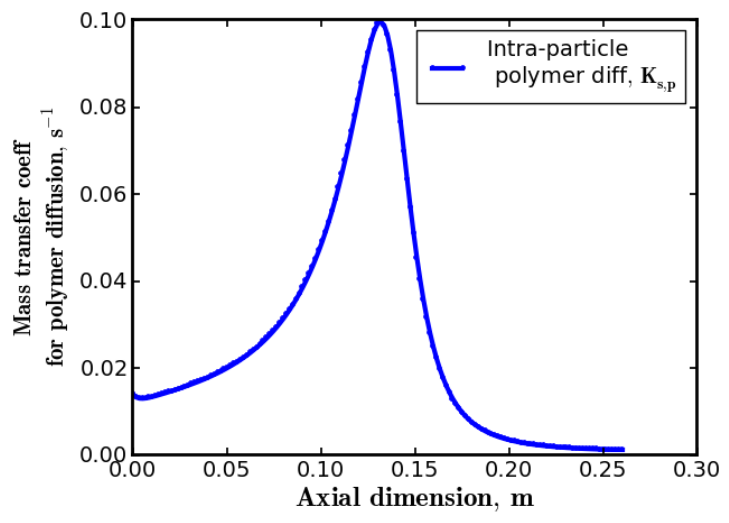

(b) Intra-particle resistance w.r.t amino-polymer diffusion (zoomed in view of the region where mass transfer coefficient $\in(0,0.1)) s^{-1}$

Figure 9: Distribution of mass transfer resistances at $\tau=60$ 


\subsection{Analysis of component transfer resistances}

Fig.9(a) shows the distribution of the different mass transfer resistances at a normalized time $\tau=60$, where the normalization of time is made with respect to the residence time as $\tau=t / t_{\text {res }}$. A zoomed in view of the region around the intra-particle resistance, $K_{s, p}$ is shown in Fig.9(b). As seen in these figures, intraparticle resistance corresponding to amino-polymer diffusion $\left(1 / K_{s, p}\right)$ is by far the dominant resistance followed by interparticle $\left(1 / K_{s, k}\right)$ (macropore) and gas phase $\left(1 / K_{g}\right)$ resistances, respectively, as both the latter are of the same order of magnitude. From this observation, we can infer the controlling steps of the overall diffusion rates; the overall mass transfer resistance for surface PEI $1 / K_{o v, k}$ in Eq.19 is dominated by the gas phases resistance $1 / K_{g}$ and inter-particle resistance $1 / K_{m}$. On the other hand, the overall mass transfer resistance for bulk PEI $1 / K_{o v, p}$ in Eq.20 is dominated solely by the intraparticle resistance $1 / K_{s, p}$.

Close inspection of the shape of the mass transfer coefficient profiles shows that gas, inter-particle and intra-particle corresponding to surface diffusion in sorbent pores (Fig.9(a)) resemble the profile of $\mathrm{CO}_{2}$ loading in sorbent 


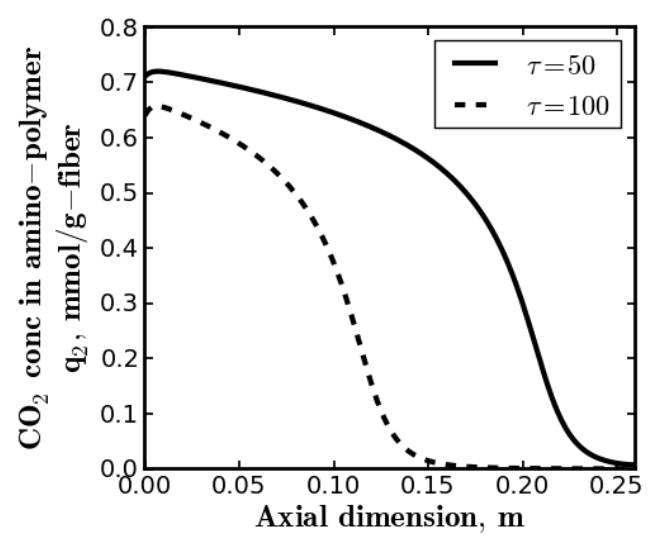

(a) $\mathrm{CO}_{2}$ loading in sorbent

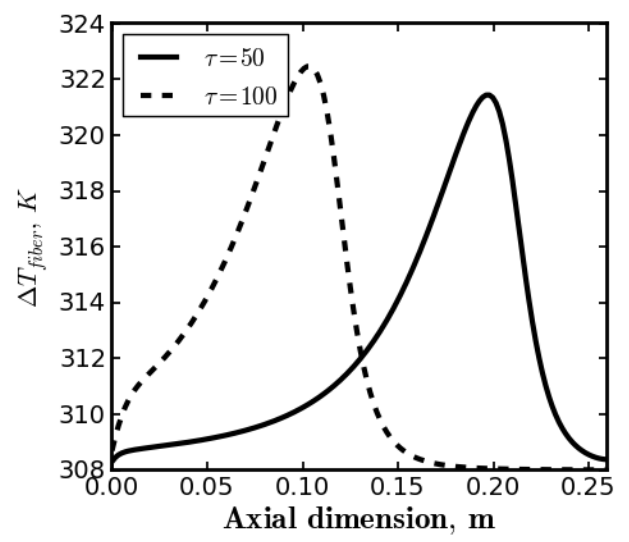

(b) Fiber temperature

Figure 10: Profile of fiber temperature and sorbent loading

as in Fig.10(a). On the other hand, the profile of intra-particle coefficient corresponding to the diffusion in the bulk PEI $\left(1 / K_{s, p}\right)$ resemble the profile of fiber temperature as in Fig.10(b). This is because as increase in temperature increases both of the terms $e^{-\alpha q_{2}}$ and $1 /\left(\partial q_{e q} / \partial C_{g, c o_{2}}\right)$, which results in the increase of $K_{s, p}$ as can been seen from Eq. 24 and Eq.31. This means that the diffusion in the bulk PEI increases with increases in temperature. This is consistent with the amino-polymer chains getting more flexible, thereby offering lesser resistance with increasing temperature. Xu et al [20] had experimentally observed an increase in $\mathrm{CO}_{2}$ adsorption capacity with increase in temperature on PEI loaded MCM-41 silica.

\subsection{Model validation}

By model validation, prediction performance of the model is rigorously assessed by comparing the model predictions against the experimental data that were not used during the parameter estimation. In this section, results 
of model validation varying the conditions such as flue gas flow rates, fiber length, fiber packing fraction in the module and silica sorbent particle size are presented. The module configuration, number of fibers and length of fiber module, corresponding to the experimental condition are mentioned in the respective sections.

\subsubsection{Varying the flue gas flow rate}

Figs.11(a) and 11(b) show the model validation against different flue gas flow rates for both $\mathrm{CO}_{2}$ breakthrough and fiber temperature profile. The runs are conducted with six fibers of length $L=10.25 \mathrm{in}$. As seen in this figure, there is an excellent agreement between the model prediction and the experimental data at different values of $Q_{\text {fluegas }}$. The temperature peak position is measure of the mass transfer resistance, where a good match is observed between the model and the experiments. This indicates a good estimation for the overall diffusion mass transfer resistance. Fig.11(c) compares the slope of the breakthrough curve between the model and the experiments along the time which is indicative of the overall diffusion mass transfer resistance [22]. It shows a very good agreement between the model and experiment. Both these validations clearly indicate that the model is able to accurately estimate the varying mass transfer resistance for this complex sorption system.

\subsubsection{Varying the fiber packing fraction}

The model performance is also tested against different fiber packing fractions $\phi$, defined as $\phi=N o_{\text {fibers }} \times\left(r_{o D}^{2}\right) / r_{\text {imod }}^{2}$, varying the number of fibers $N o_{\text {fibers }}$ within the module. Here $r_{\text {imod }}$ is the cross section radius of the module. The fiber length is maintained at $L=10.25 \mathrm{in}$ and the number of fibers is 

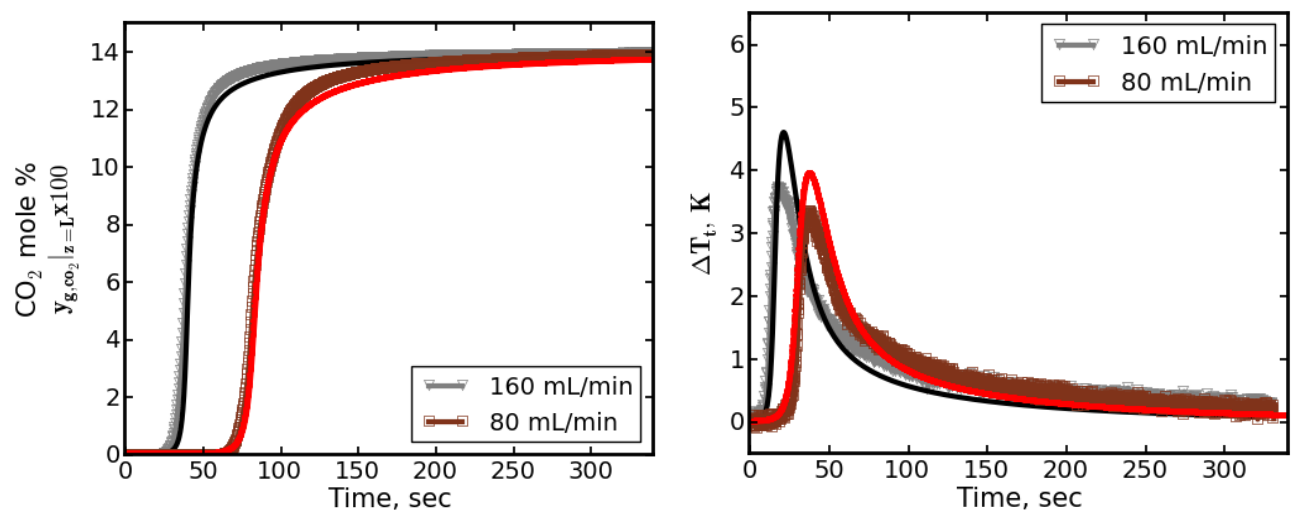

(a) $\mathrm{CO}_{2}$ breakthrough profile

(b) Fiber temperature profile at $\mathrm{z}=4.5$

in

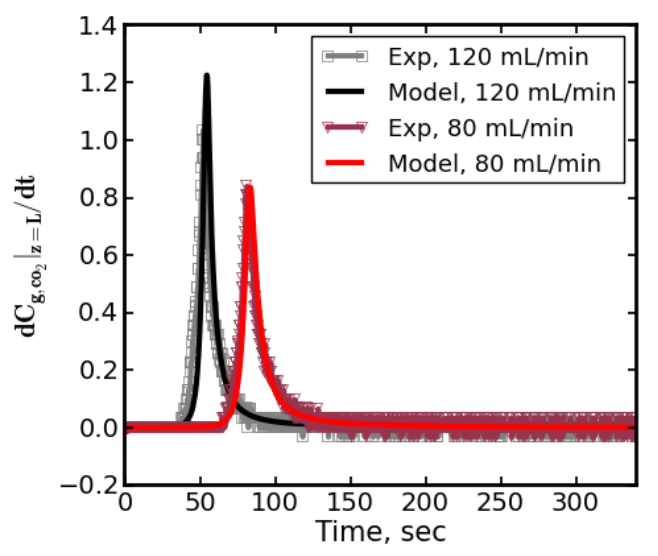

(c) Time derivative of concentration at the fiber exit

Figure 11: Model validation at different flue gas flow rates $\left(Q_{\text {fluegas }}\right)$, solid line is model prediction, $L=10.25 \mathrm{in}$ 

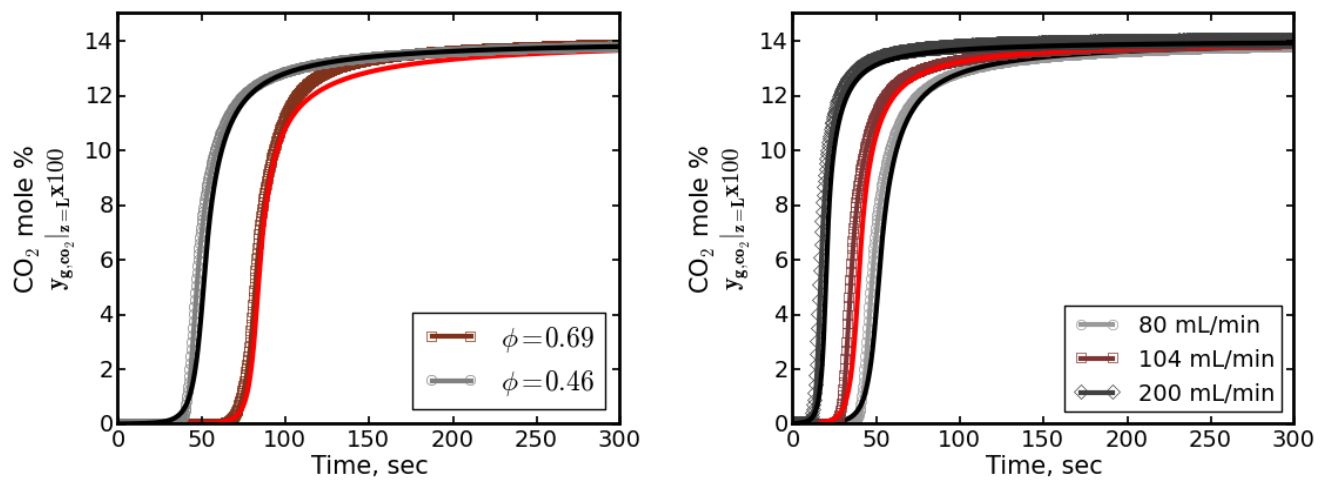

(a) $\mathrm{CO}_{2}$ breakthrough for $Q_{\text {fluegas }}=80$ (b) $\mathrm{CO}_{2}$ breakthrough for various $Q_{\text {fluegas }}$ sccm at different $\phi$ at $\phi=0.46$

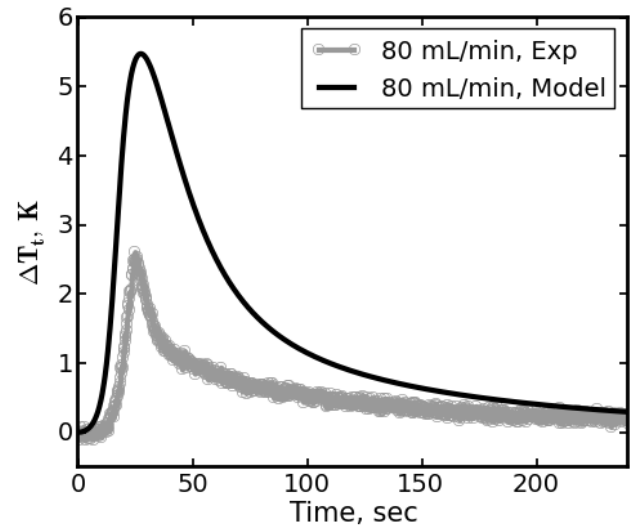

(c) Temperature profile at $\mathrm{z}=4.5$ in for $\phi=0.46$

Figure 12: Model validation at different packing fraction $\phi$, solid line without marker is model prediction at corresponding condition, $L=10.25 \mathrm{in}$ 
reduced from six to four to give $\phi=0.46$. Fig.12(a) shows the model prediction of $\mathrm{CO}_{2}$ breakthrough for the two different packing fractions at the same $Q_{\text {fluegas. }}$ In addition, Fig.12(b) shows the model prediction performance at the lower packing fraction $\phi=0.46$ for different flue gas flow rates. It is to be noted that the model validation in the previous section in Fig.11(b) was for $\phi=0.69$. Overall, the model prediction matches very well for different packing fractions as well as across different flue gas flow rates. In Fig.12(c), the temperature profile is compared between the model prediction and the experiment. As observed, the model matches very well with experiment with respect to the peak position and has a mismatch with respect to the peak height. This is probably because the heat loss model does not account for all possible modes of heat transfer from the labscale module, such as conduction between the fibers and from the fiber ends, which are ignored in the current model.

\subsubsection{Varying the fiber length}

Three different fiber lengths viz. $L=10.25 \mathrm{in}, 17.0 \mathrm{in}$ and $L=34.0 \mathrm{in}$ were tested and $\mathrm{CO}_{2}$ breakthrough data were collected and compared against the model prediction. The packing fraction of the modules is fixed at $\phi=0.69$ with six fibers. Fig.13(a) shows the model prediction against the experimental data at different fiber lengths for a fixed flue gas flow rate. In addition, the model performance is also tested at different $Q_{\text {fluegas }}$ in Fig.13(b) for the higher fiber length $L=17.0 \mathrm{in}$. In both the cases, the model performs very well having a very good match with experiments across different fiber lengths. Similarly to the packing fraction case, thermal peak as shown in Fig.13(c) has a mismatch between the model and the experiments for the 

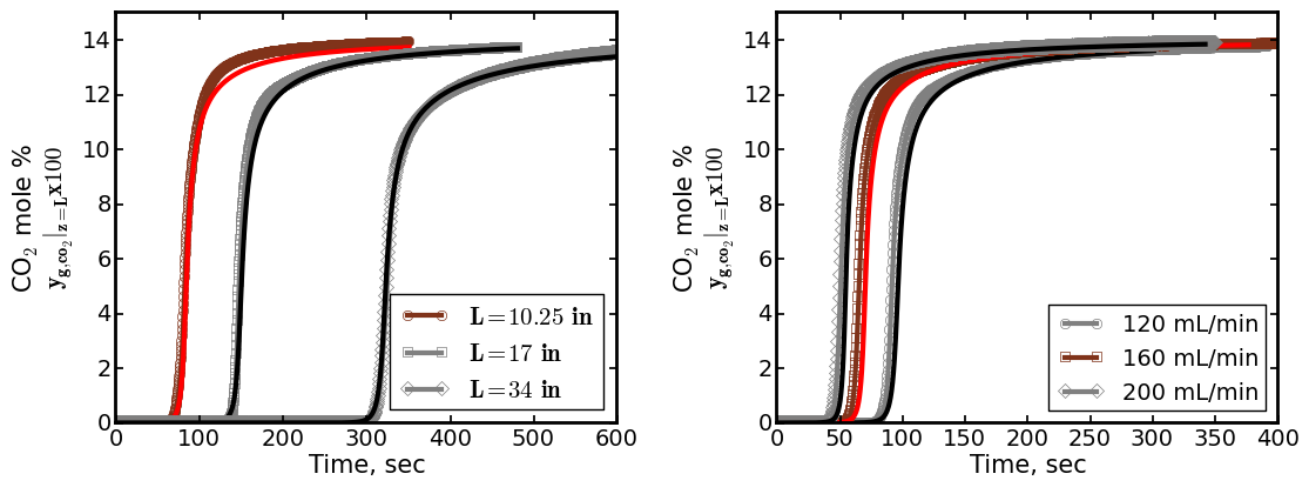

(a) $\mathrm{CO}_{2}$ breakthrough for $Q_{\text {fluegas }}=80$ (b) $\mathrm{CO}_{2}$ breakthrough for various $Q_{\text {fluegas }}$ $\mathrm{mL} / \mathrm{min}$ with varying $L$ with $L=17.0 \mathrm{in}$

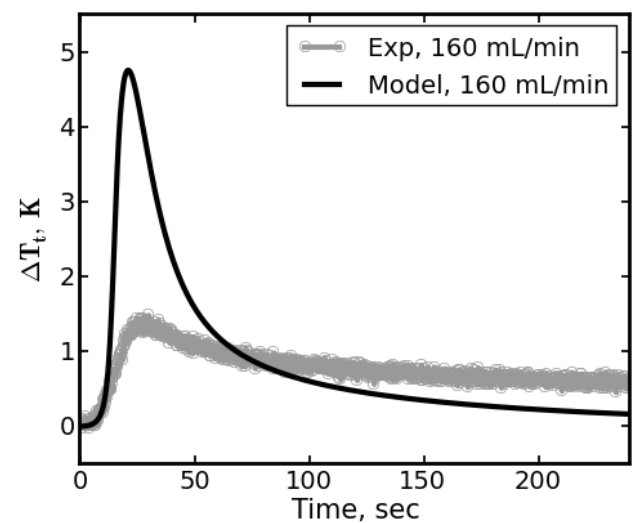

(c) Temperature profile at $\mathrm{z}=4.5$ in with $L=17.0 \mathrm{in}$

Figure 13: Model validation at different fiber length $L$, solid line without marker is model prediction 
same reason as mentioned above. Again, the peak position of thermal profile has a good match between the model and the experiment.

\subsubsection{Varying the sorbent particle size}
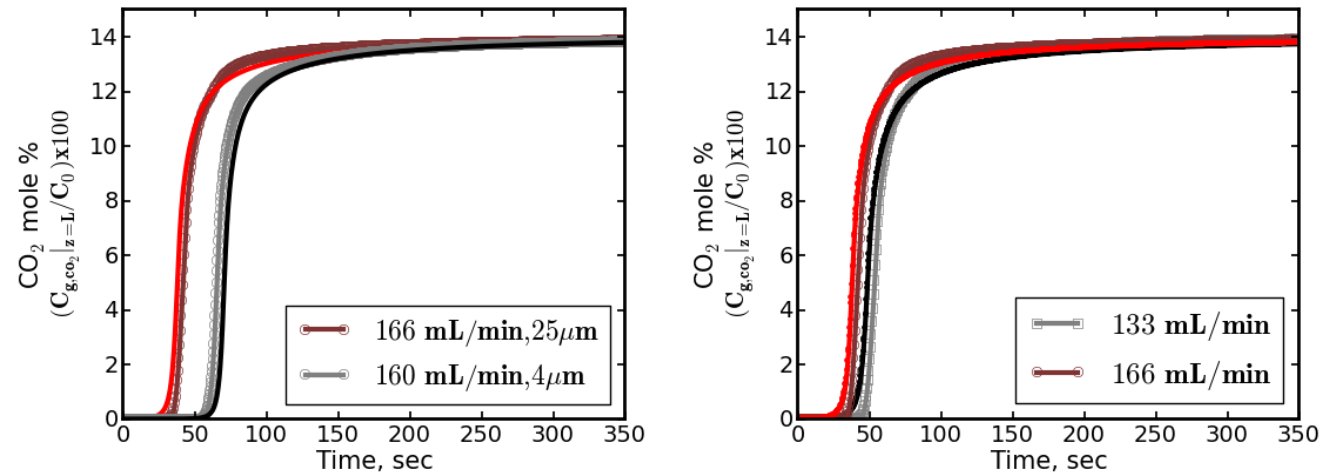

(a) $\mathrm{CO}_{2}$ breakthrough for $Q_{\text {fluegas }}$

160 (b) $\mathrm{CO}_{2}$ breakthrough for various $Q_{\text {fluegas }}$ sccm at varying $d_{s}$ at $d_{s}=25 \mu \mathrm{m}$

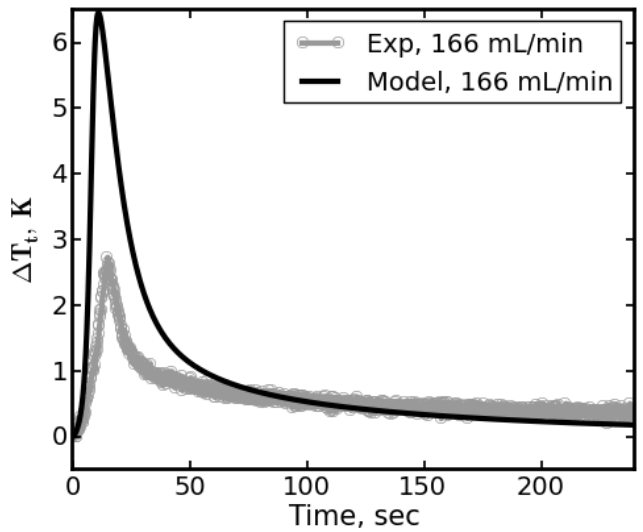

(c) Fiber temperature profile for $d_{s}=25 \mu \mathrm{m}$ at $\mathrm{z}=4.5$ in

Figure 14: Model validation at different particle size $d_{s}$, solid line without marker is model prediction at corresponding condition 


\begin{tabular}{cccccc}
\hline Particle & $d_{s}, \mu \mathrm{m}$ & $L$, in & $\left(d_{I D}, d_{o D}\right), \mu \mathrm{m}$ & $\psi$ & $N o_{\text {fibers }}$ \\
\hline C803 & 4.0 & 17.0 & $550.0,1305.0$ & 0.17 & 6 \\
ES757 & 25.0 & 17.0 & $550.0,1305.0$ & 0.23 & 5 \\
\hline
\end{tabular}

Table 4: Process parameters for both the particles

In this study, the most challenging parameter that influences the mass transfer kinetics is the particle size of support silica. The experiments in the previous sections have been conducted with C803 particles of the diameter of $d_{s}=4 \mu \mathrm{m}$ as molecular baskets for PEI. Here, we also test ES757 which has a significantly larger particle size of $d_{s}=25 \mu \mathrm{m}$ as molecular baskets for PEI. The parameter $\psi$, denoting the fraction of the amine sites on the surface for ES757 fiber is estimated to be 0.23 in the same manner as C803 particle using the corresponding measurements available in Ying et al (see Appendix A). The process parameters corresponding to the two different particles are listed in Table.4. Fig.14(a) shows the breakthrough profiles at a given flow rate for both the particle sizes and Fig.14(b) shows the model performance at different flow rates $Q_{\text {fluegas }}$ for the larger particle size ES757. As seen in the figures, the model performs very well for different sorbent particle sizes as well and across different flue gas flow rates.

\subsection{Temperature effect on breakthrough capacity}

Based on thermodynamics of the exothermic systems such as adsorption process, the equilibrium and hence the breakthrough capacity $q_{b}$ is expected to decrease with temperature as is observed in all of the conventional sorbents. To the contrary, Fan et al [8] had reported a concave trend where the breakthrough capacity increases with increase in temperature over some 
range for PEI impregnated hollow fiber based amine sorbents. They reported the highest capacity at around $45^{\circ} \mathrm{C}$ and drop in capacity on further temperature increase. Earlier $\mathrm{Xu}$ et al [20] reported a similar observation for MCM-41 supported PEI sorbents. In order to investigate the trend, the de-

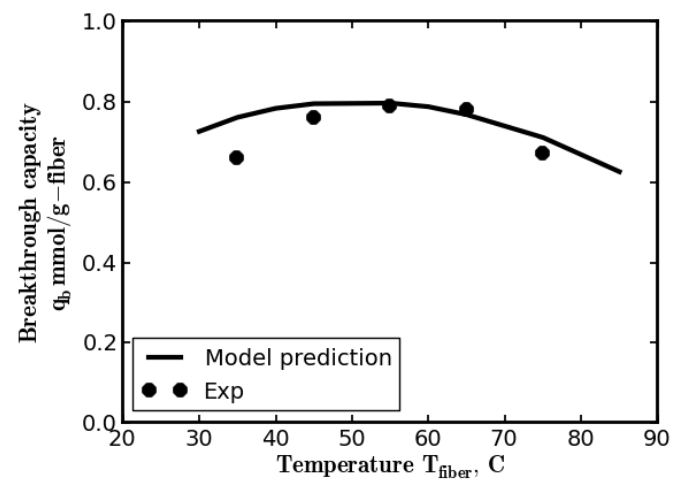

Figure 15: Model prediction of $q_{b}$ at different initial fiber temperatures $T_{f 0}$

veloped model is used to determine the breakthrough capacity at different temperatures and plotted as shown in Fig.15. Breakthrough capacity is defined as the total number of $\mathrm{CO}_{2}$ moles adsorbed per unit mass of fiber until breakthrough time $t_{b}$, which is the time instant at which the exit concentration reaches $5 \%$ of the inlet concentration, $C_{0}$ and is defined as time $t$ at which $\left.C_{g, c_{2}}\right|_{z=L}=0.05 C_{0}$ is satisfied. The breakthrough capacity, $q_{b}$ is calculated using the following equation.

$$
q_{b}=\frac{2}{\left(r_{o D}^{2}-r_{I D}^{2}\right) L} \int_{t=0}^{t_{b}} \int_{r_{I D}}^{r_{o D}} \int_{z=0}^{z=L} \frac{\partial q}{\partial t} r d r d z d t
$$

As seen in Fig.15, $q_{b}$ predicted by the model increases as the temperature increases from $30^{\circ} \mathrm{C}$ and reaches a maximum at around $45{ }^{\circ} \mathrm{C}-60{ }^{\circ} \mathrm{C}$ 


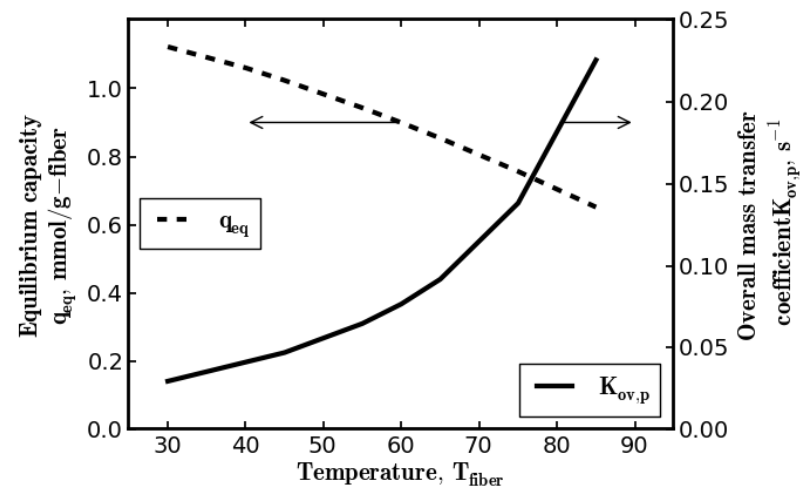

Figure 16: Temperature effect on overall diffusion resistance and equilibrium capacity

and starts to decrease on further increase of temperature. It qualitatively matches the trend observed experimentally as seen in the figure. This can be explained by the two competing factors, the equilibrium capacity $q_{e q}$ and the intraparticle diffusion resistance $1 / K_{o v, p}$ which are plotted as shown in Fig.16. As observed, the mass transfer coefficient $K_{o v, p}$ increases with temperature whereas the equilibrium concentration, and hence the driving force decreases with temperature. This implies that at lower temperatures, the lower capacity is due to the dominating effect of higher diffusion resistance (or lower $K_{o v, p}$ ) and at the higher temperatures, the lower capacity is due to the controlling effect of thermodynamic equilibrium. Both the effects balance each other around $45{ }^{\circ} \mathrm{C}-60{ }^{\circ} \mathrm{C}$ when the breakthrough capacity $q_{b}$ reaches a maximum value as observed.

\section{Summary}

A rigorous mathematical mass transfer model was developed for $\mathrm{CO}_{2}$ adsorption on hollow fibers post infused with poly(ethylenimine) loaded meso- 
porous silica sorbents (molecular baskets). PEI loaded silica sorbents were assumed to contain two different regions of amines sites, including the ones which are dispersed on the surface on the silica sorbent pores (surface PEI) and those that are confined within the amino-polymer phase of the sorbent particle (bulk PEI). The fraction of the PEI amine sites on the pore surface of the silica particles of interest, C803 and ES757 were calculated based on the measurements of Wang et al [10] and Ying et al [15]. The LDF model was considered for the two sites separately accounting for their respective overall diffusion mass transfer resistances. Further, a model analogous to the free volume theory of polymers was used to define the polymer diffusivity coefficient, where diffusivity reduces with the $\mathrm{CO}_{2}$ loading in the amino-polymer region of the sorbent. Also, the diffusion coefficient was considered to be dependent on temperature according to the Arrhenius equation.

The model, thus developed was rigorously validated under varying operating conditions and module configurations such as different flue gas flow rate, number of fibers in the module, length of the fibers and size of the silica particle containing the poly(ethylenimine). Under all the different conditions, the model matches very well with the experimental data and therefore can be used further for process analysis, scalability and optimization. Furthermore, the model was used to explain the concave trend in the temperature dependency of breakthrough capacity of PEI impregnated amine sorbents. The analysis using the model suggests that the interplay between the intra-particle polymer diffusion and adsorption equilibrium causes the concave trend in the temperature dependency of breakthrough capacity. Future studies would include the validation of the model with desorption of $\mathrm{CO}_{2}$ 
from the bed and to extend the model to include the wet flue gas adsorption and desorption. 


\section{Nomenclature}

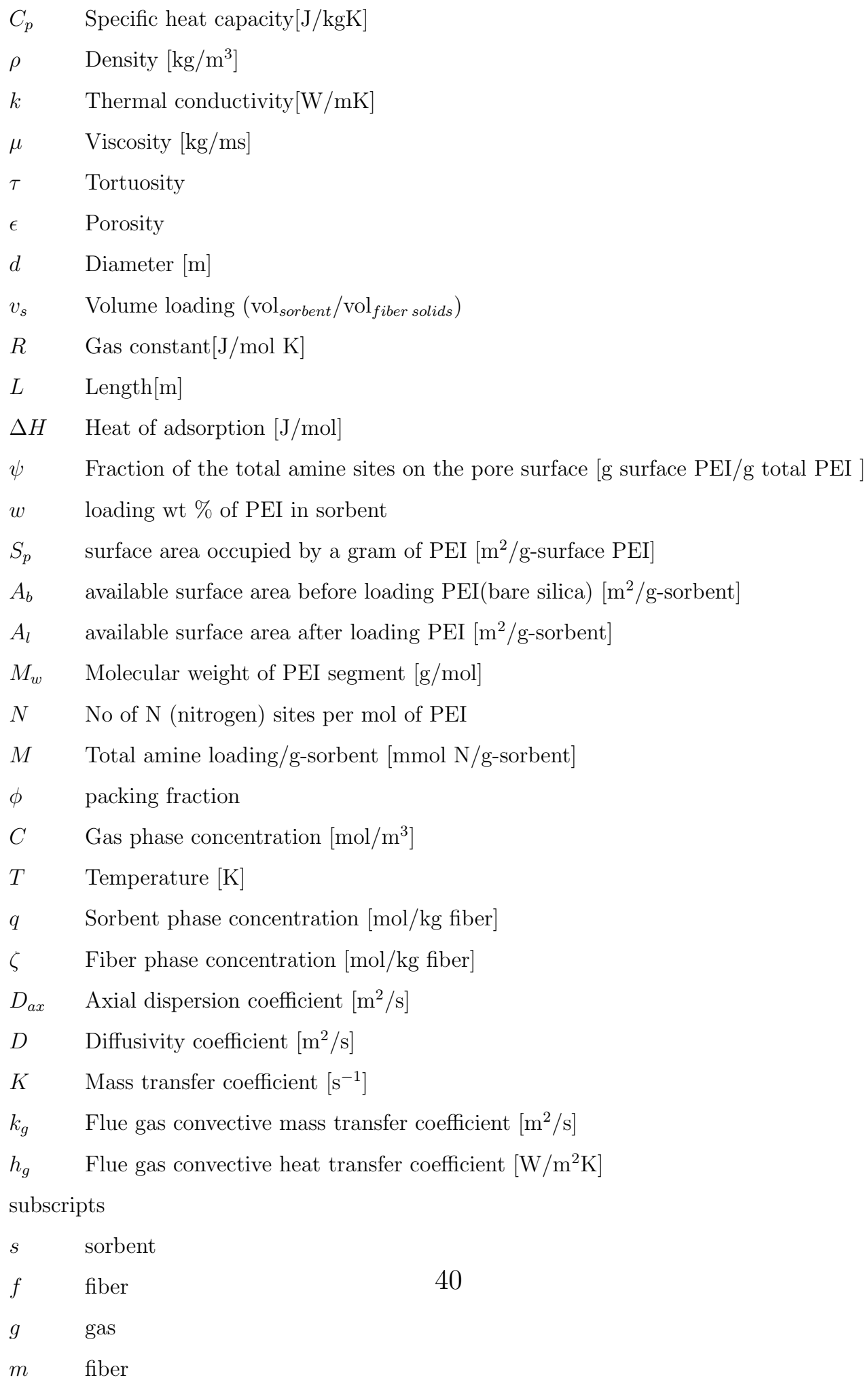




\section{Acknowledgment}

The authors would like to thank the US Department of Energy for supporting this work (Grant number DE-FE0007804).

\section{Appendix A. Estimation of $\psi$ for C803 and ES757}

The values for the parameters along with their references are listed in Table.A.5.

Table A.5: Values of parameters for estimating $\psi$

\begin{tabular}{|c|c|c|}
\hline Parameters & Symbols & Values \\
\hline Fraction of total amine sites on surface & $\psi^{s b a-15}$ at $40^{\circ} \mathrm{C}$ at $50 \mathrm{wt} \%$ & $0.64[10]$ \\
\hline Surface area after loading (SBA-15) & $A_{l}^{s b a-15}$ & $1000 \mathrm{~m}^{2} / \mathrm{g}$-sorbent [11] \\
\hline Surface area before loading (SBA-15) & $A_{b}^{s b a-15}$ & $80 \mathrm{~m}^{2} / \mathrm{g}$-sorbent $[11]$ \\
\hline Surface area before loading (C803) & $A_{b}^{c 803}$ & $209 \mathrm{~m}^{2} / \mathrm{g}$-sorbent $[15]$ \\
\hline Surface area before loading (C803) & $A_{l}^{c 803}$ & $37 \mathrm{~m}^{2} /$ g-sorbent $[15]$ \\
\hline Surface area before loading (ES757) & $A_{b}^{e s 757}$ & $295 \mathrm{~m}^{2} / \mathrm{g}$-sorbent $[15]$ \\
\hline Surface area before loading (ES757) & $A_{l}^{e s 757}$ & $23 \mathrm{~m}^{2} / \mathrm{g}$-sorbent $[15]$ \\
\hline Molecular weight of PEI segment & $M_{w}$ & $423 \mathrm{~g} / \mathrm{mol}-\mathrm{PEI}[11]$ \\
\hline No of amine sites per mol of PEI & $N$ & 11 \\
\hline Total amine loading (C803) & $M^{c 803}$ & $9.54 \mathrm{mmol} \mathrm{N} / \mathrm{g}$-sorbent $[15]$ \\
\hline Total amine loading (ES757) & $M^{e s 757}$ & $10.6 \mathrm{mmol} \mathrm{N} / \mathrm{g}$-sorbent [15] \\
\hline
\end{tabular}

The surface area lost on loading the silica with PEI is given by $A_{b}-A_{l}$, where $A_{b}$ and $A_{l}$ are the surface areas of the silica before and after loading the sorbent. Let $S_{p}$ be the surface area occupied by a unit weight of surface PEI and $w$ be the weight $\%$ sorbent loading in the silica. Now, the fraction of total amine sites (total PEI) available on the surface of the sorbent pores 
(surface PEI) can be determined as follows.

$$
\psi=\frac{\left(A_{b}-A_{l}\right)}{S_{p} w}
$$

Here $S_{p}$, the surface area occupied by a unit weight of surface PEI is the characteristic parameter for which the value is unknown. To determine the value of $S_{p}$, the data obtained using temperature programmed desorption experiment by Wang et al [11] with the PEI loaded SBA-15 are used. $S_{p}$ is given by the following equation and is calculated as $2875 \mathrm{~m}^{2} / \mathrm{g}$-surface PEI.

$$
S_{p}=\frac{\left(A_{b}^{s b a-15}-A_{l}^{s b a-15}\right)}{\psi^{s b a-15} w^{s b a-15}}
$$

Knowing $S_{p}$, the fraction of total amine sites available on the surface of the sorbent pores can be calculated for any silica using Eq.A.1. Here, $w$ for the silica particle of interest can be calculated using the following relation $w=M M_{w} / N$, as the measurements are available for the total amine loading in the sorbent $M$. As the amine loading is typically reported as mmol $\mathrm{N}$ (nitrogen)/g-sorbent, the conversion factors of molecular weight of PEI $M_{w}$ and number of $\mathrm{N}$ ( nitrogen) sites available per mol of PEI are used to obtain $w$. It is to be noted that the estimates are solely based on the value of $\psi$ reported by Wang et al[10] for SBA-15 using temperature programmed desorption. Therefore, the value of $\psi$ estimated may be subject to substantial uncertainty.

\section{References}

[1] H. Yang, Z. Xu, M. Fan, R. Gupta, R.B. Slimane, A.E. Bland, I .Wright, Progress in carbon dioxide separation and capture : A review, Journal of Environmental Sciences, 20(2008),14-27. 
[2] D.J. Fauth, M.L. Gray, H.W. Pennline, H.M. Krutka, S. Sjostrom, A.M. Ault, Investigation of porous silica supported mixed-amine sorbents for post-combustion $\mathrm{CO}_{2}$ capture, Energy and Fuels, 26(2012),2483-2496.

[3] R.P. Lively, R.R. Chance, J. Mysona, V.P. Babu, H.W. Deckman, D.P. Leta, H. Thomann, W.J. Koros, CO2 sorption and desorption performance of thermally cycled hollow fiber sorbents, International Journal of Greenhouse Gas Control, 10(2012),285-294.

[4] R.P. Lively, R.R. Chance, W.J. Koros, Enabling low-cost $\mathrm{CO}_{2}$ capture via heat integration, Ind. Eng. Chem. Res, 49(2010),7550-7562.

[5] S. Choi, J.H. Drese, C.W.Jones, Adsorbent materials for carbon dioxide capture from large anthropogenic point sources, ChemSusChem, 2(2009),796-854.

[6] P. Bollini, S. Didas, C.W. Jones, Amine-oxide hybrid materials for acid gas separations, J. Mater. Chem., 21(2011), 15100-15120.

[7] F. Rezaei, R.P. Lively, Y. Labreche, G. Chen, Y. Fan, W.J. Koros, C.W. Jones, Aminosilane-grafted polymer/silica hollow fiber adsorbents for $\mathrm{CO}_{2}$ capture from flue gas, ACS applied materials and interfaces, 5(2013), 3921-31.

[8] Y. Fan, R.P. Lively, Y. Labreche, F. Rezaei, W.J. Koros, C.W. Jones, Evaluation of CO 2 adsorption dynamics of polymer / silica supported poly ( ethylenimine ) hollow fiber sorbents in rapid temperature swing adsorption, International Journal of Greenhouse Gas Control, 21(2014),61-71. 
[9] P. Bollini, N.A. Brunelli, S.A. Didas, C.W. Jones, Dynamics of $\mathrm{CO}_{2}$ adsorption on amine adsorbents. 2. insights into adsorbent design, Ind. Eng. Chem. Res, 51(2012),15153-15162.

[10] X. Wang, C. Song, Temperature-programmed desorption of CO2 from polyethylenimine-loaded SBA-15 as molecular basket sorbents, Catalysis Today, 194(2012), 44-52.

[11] X. Wang, X. Ma, C. Song, D.R. Locke, S. Siefert, R.E. Winans, J. Mllmer, M. Lange, A. Mller, R. Glser, Molecular basket sorbents polyethylenimine-SBA-15 for CO2 capture from flue gas: Characterization and sorption properties, Microporous and Mesoporous Materials, 169(2013),103-111.

[12] R. Serna-Guerrero, A. Sayari, Modeling adsorption of CO2 on aminefunctionalized mesoporous silica. 2: Kinetics and breakthrough curves, Chemical Engineering Journal, 161(2010), 182-190.

[13] F. Rezaei, S. Subramanian, J. Kalyanaraman, R.P. Lively, Y. Kawajiri, M.J. Realff, Modeling of rapid temperature swing adsorption using hollow fiber sorbents, Chemical Engineering Science, 113(2014), 62-76.

[14] A.D. Ebner, M.L. Gray, N.G. Chisholm, Q.T. Black, D.D. Mumford, M.A. Nicholson, J.A. Ritter, Suitability of a solid amine sorbent for $\mathrm{CO}_{2}$ capture by pressure swing adsorption, Ind. Eng. Chem. Res, 50(2011), 5634-5641.

[15] Y. Labreche, R.P. Lively, F. Rezaei, G. Chen, C.W. Jones, and Koros, W.J., Post-spinning infusion of poly(ethyleneimine) into polymer/silica 
hollow fiber sorbents for carbon dioxide capture, Chemical Engineering Journal, 221(2013),166-175.

[16] J. Happel, Viscous flow relative to arrays of cylinders, AICHE Journal, 5(1959),174-177.

[17] A. Asimakopoulou, A. Karabelas, A study of mass transfer in hollowfiber membrane contactors-The effect of fiber packing fraction, Journal of Membrane Science, 282(2006),430-441.

[18] J. Welty, C.E. Wicks, R.E. Wilson, G.L. Rorrer, Fundamentals of momentum, heat and mass transfer, John Wiley and Sons, Inc, 5th ed., 2008.

[19] H. Fujita, A.J. Kishimoto, Diffusion-Controlled Stress Relaxation in Polymers. II. Stress Relaxation in Swollen Polymers, Journal of Polymer Science, 28(2014),547-559.

[20] X. Xu, C. Song, J.M. Andresen, B.J. Miller, A.W. Scaroni, Novel polyethylenimine-modified mesoporous molecular sieve of MCM-41 type as high-capacity adsorbent for CO2 capture, Energy and Fuels, 16(2002),1463-1469.

[21] Process Systems Enterprise, L., gPROMS Model Developer Guide, v3.4.0 ed, Process Systems Enterprise Limited, London,2011.

[22] D.M. Ruthven, S. Farooq, K.S. Knaebel, Pressure Swing Adsorption, John Wiley and Sons Inc., 1993 
[23] P. Fatos, G. Alain, C. Renaud, B. Chakib, R. Dominique, Kinetics of absorption of $\mathrm{CO}_{2}$ in concentrated aqueous methyldiethanolamine solutions in the range $296 \mathrm{~K}$ to $343 \mathrm{~K}$, Journal of Chem. Engg. Data, 42(1997), 453-459. 